\title{
The Female Athlete Triad - the impact of running and type of diet on the regularity of the menstrual cycle assessed for recreational runners
}

\author{
Joanna Witkoś ${ }^{\text {Corresp., } 1}$, Magdalena Hartman-Petrycka ${ }^{2}$ \\ ${ }^{1}$ Faculty of Medicine and Health Science, Andrzej Frycz Modrzewski Krakow University, Kraków, Poland \\ 2 Department of Basic Biomedical Science, Faculty of Pharmaceutical Sciences in Sosnowiec, Medical University of Silesia, Katowice, Poland \\ Corresponding Author: Joanna Witkoś \\ Email address: jwitkos@afm.edu.pl
}

Background. The Female Athlete Triad (FAT) included three interrelated conditions including disordered eating, amenorrhea, and osteoporosis. The American College of Sports Medicine updated the definition of FAT to reflect the interdependence of low energy availability with or without eating disorders. The main aim of the study was to assess the impact of recreational running on potential disturbances in the regularity of women's menstrual cycles. Additionally, this work compared differences in the menstrual cycle between women runners and women who did not regularly practice sports. The respondents were also asked about the type of diet they consumed. Methods. A total of 360 women took part in the research. This group included 217 runners and 143 control. The authors' questionnaire was used in the research. Results. When compared to the control group, the runners had an increased frequency of menstrual cycles of $<24$ days ( $10.14 \%$ vs. $3.50 \%)$, fewer typical cycles of $25-31$ days $(75.58 \%$ vs. $86.71 \%)$, had fewer regular cycles per year (9.62 vs. 11.22), shorter duration of bleeding (4.79 vs. 5.27 days), and an increased frequency of painless menstruation (23.96\% vs.7.69\%). A positive predictor of menstrual cycle disorders was the use of a 'special diet' (R:1.67; 95\% C:0.47-2.87). Conclusions. The runners had shorter and less regular monthly cycles and shorter and more often painless menstrual bleeding when compared to the control group. The frequency of menstrual disorders in runners was increased by following a 'special diet'. The frequency of menstrual cycle disorders in runners, however, did not differ significantly from the control group. 
1 The Female Athlete Triad - the impact of running and type of diet on the regularity of the

2 menstrual cycle assessed for recreational runners

3

4 Joanna Witkoś', Magdalena Hartman-Petrycka²

$6{ }^{1}$ Faculty of Medicine and Health Science, Andrzej Frycz Modrzewski Krakow University, 7 Kraków, Poland

8 2Department of Basic Biomedical Science, Faculty of Pharmaceutical Sciences in Sosnowiec, 9 Medical University of Silesia, Katowice, Poland

Abstract

Background. The Female Athlete Triad (FAT) included three interrelated conditions including disordered eating, amenorrhea, and osteoporosis. The American College of Sports Medicine updated the definition of FAT to reflect the interdependence of low energy availability with or without eating disorders. The main aim of the study was to assess the impact of recreational running on potential disturbances in the regularity of women's menstrual cycles. Additionally, this work compared differences in the menstrual cycle between women runners and women who did not regularly practice sports. The respondents were also asked about the type of diet they consumed.

Methods. A total of 360 women took part in the research. This group included 217 runners and 143 control. The authors' questionnaire was used in the research.

22 Results. When compared to the control group, the runners had an increased frequency of menstrual cycles of $<24$ days (10.14\% vs. 3.50\%), fewer typical cycles of $25-31$ days $(75.58 \%$ vs. $86.71 \%$ ), had fewer regular cycles per year (9.62 vs. 11.22), shorter duration of bleeding (4.79 vs. 5.27 days), and an increased frequency of painless menstruation (23.96\% vs.7.69\%). A positive predictor of menstrual cycle disorders was the use of a 'special diet' (R:1.67; 95\% $\mathrm{C}: 0.47-2.87)$.

Conclusions. The runners had shorter and less regular monthly cycles and shorter and more often painless menstrual bleeding when compared to the control group. The frequency of 
30

31

32

33

34

35

36

37

38

39

40

41

42

43

44

45

46

47

48

49

50

51

52

53

54

55

56

57

58

59

60

menstrual disorders in runners was increased by following a 'special diet'. The frequency of menstrual cycle disorders in runners, however, did not differ significantly from the control group.

\section{Introduction}

Many health benefits, both sociological as well as psychological, are associated with the systematic participation in physical activity. An imbalance, however, between the level of energy supplied by the diet and the body's energy expenditure leads to serious health effects (Mountjoy et al., 2018).

The Female Athlete Triad (FAT) was first defined in 1992 and included three interrelated conditions including disordered eating, amenorrhea, and osteoporosis. In 2007, the American College of Sports Medicine updated the definition of FAT to reflect the interdependence of low energy availability (LEA) (with or without eating disorders) with amenorrhea, decreased bone mineral density, and osteoporosis, which may result in the non-simultaneous occurrence of the clinical symptoms (Matzkin et al., 2015; De Souza et al., 2017; Beals et al., 2017; Daily et al., 2018; Williams et al., 2017; Stefani et al., 2016; George et al., 2011). Subsequently, in 2014, the International Olympic Committee reported the syndrome referred to as relative energy deficiency in sport (RED-S), which highlighted the impact of low energy availability on the human body and recognized FAT as one of the outcomes of LEA in the RED-S model (Mountjoy et al., 2018).

In a situation of high energy expenditure, such as that related to participation in sports, an insufficient energy intake from food results in an energy deficit. This deficit inhibits reproductive functions and results in a state referred to as functional hypothalamic amenorrhea.

Occurrence of the three interrelated physiological effects related to LEA has been repeatedly documented and discussed in the research (Schofield et al., 2020; Sim et al., 2021; Civil et al., 2018). Currently, however, it has been suggested that the presence of at least one component of the FAT in women who practice sports is sufficient to define FAT, because symptoms of the related physiological impacts occur with a different intensity and may appear at different times depending on the athlete's diet and training load (Williams et al., 2019). Research has shown that the prevalence of any one component of FAT ranged from $16 \%$ to $60 \%$ and any two from $3 \%$ to $27 \%$, which shows that, for most female athletes, the individual components of 
61 FAT may have different time sequences and not always appear simultaneously (Matzkin et al., 62 2015; De Souza et al., 2017; Beals et al., 2017; Daily et al., 2018; Williams et al., 2017; Stefani 63 et al., 2016). The simultaneous incidence of all components of FAT is relatively low and varies.

64 A report that reviewed the literature related to single and combined triad markers reported that 65 the incidence of energy deficiency and disordered eating was $0 \%-48 \%$ and $7.1 \%-89.2 \%$,

66

67

68 69 respectively (Williams et al., 2017).

Until recently, FAT studies only included women in competitive training since it was believed that only professional athletes were susceptible to developing the triad. It is now known that the occurrence of the FAT syndrome may also affect women who are not elite athletes, and the severity of the syndrome varies depending on the type of sport a woman undertakes. It has been shown that FAT most often affects women who take part in those sports and physical activities that include an aesthetic element that favors a slim figure and low body weight, such as artistic gymnastics, figure skating, and also ballet and dance (Tosi et al., 2019). These require both a large energy expenditure and a slim, shapely figure. It has also been shown that high morbidity affects women participating in endurance sports, such as cross-country running, crosscountry skiing, and the triathlon (Castelo-Branco et al., 2006; Sawai et al., 2018; Lynch et al., 2007; Thompson 2007).

Due to the fact that women today participate in sport at all levels, it has been suggested that more emphasis should be placed on educating women about the occurrence of the FAT (Westerbeek 2009). Most of the scientific literature on RED-S or FAT focuses on professional athletes and does not check the prevalence of, for example, FAT in women who engage in recreational sports. Running is a physical activity that is generally available to most people and can be practiced as a stand-alone sport or as an integral part of many training programs. Shortand long-distance running are employed as both recreational and professional sports. Women undertake sports activities for many reasons, including typical sports rivalry (competitions, marathons, olympics), but also for recreational purposes, social interactions, health reasons such as weight reduction, and improvement of general physical fitness. Physically active women are generally healthier than people leading a sedentary lifestyle and have greater self-confidence that results from an increase in their self-esteem and physical attractiveness (Macleod 1998). Moreover, sport, especially when undertaken on a recreational basis, prevents depression and anxiety (Tosi et al., 2019; Sawai et al., 2018; Lynch et al., 2020; Thompson 2007). Regardless of 
92 the motivation for this type of physical activity, it is important to understand the impact that 93 running can have on the overall health of women who run for recreational purposes.

94 The main aim of the study was to assess the impact that recreational running has on 95 potential disturbances in the regularity of women's menstrual cycles. Additionally, it evaluated 96 the differences in the menstrual cycle experienced by women who ran compared with women 97 who did not regularly practice sports. A question was also asked about the runners' knowledge of 98 FAT.

Materials \& Methods

\section{Participants}

The study involved 217 women who regularly run (Group R), 32.1 8.4 years, and 143 women in a control group (Group C) $31.9 \pm 8.8$ years. The women in Group R had been running on average (median) for 4 years. The minimum distances covered by the runners were, on average, $5 \mathrm{~km}$, and the maximum $15 \mathrm{~km}$. The women declared that their runs usually lasted an hour, and that they ran a minimum of three and a maximum of four times per week. All of the running, both short and long distances, was done outdoors. The vast majority of women from group C, about $90 \%$, declared that they did not practice any sports activity on a regular basis. The remaining women in Group C only exercised rarely and irregularly. Their total weekly training time did not exceed 1.5 hours. A summary of these attributes is presented in Table 1 . Most of the respondents from both groups lived in Kraków and its vicinity, in the Małopolska Voivodeship (Lesser Poland voivodeship). Some of the women also came from the neighboring Śląsk Voivodeship (Upper Silesian voivodeship). They were mainly students from the university as well as their family and friends.

In both groups, the criteria for exclusion from the study was the use of hormonal contraception, or the declaration of amenorrhea caused by menopause, or another known factor not directly related to physical exercise such as hysterectomy, pregnancy, or polycystic ovary syndrome. The lack of a correctly completed questionnaire also resulted in exclusion from the research.

Participation in the research was voluntary and anonymous in accordance with the Declaration of Helsinki and the participants were informed about the purpose of the research and their right to refuse to answer the survey questions. The research protocol was reviewed 
123

124

125

126

127

128

129

130

131

132

133

134

135

136

137

138

139

140

141

142

143

144

145

146

147

148

149

150

151

and approved by the Bioethical Committee of the Andrzej Frycz Modrzewski Krakow University (Permission number KBKA/93/O/2020). The study utilized a survey conducted online using Google Forms. Hence, the participants were anonymous to the authors of the study and vice versa. There was no way of receiving informed consent from the participants. The questionnaire was completed by volunteers who wanted to share their own experience about menstrual disorders.

\section{Questionnaire}

The questionnaire utilized in this study was composed by the authors. This was an unvalidated questionnaire that was used for the measurement of cycle changes. The original and English language translation of the questionnaire administered to study participants is included as supplementary material. The research was conducted on-line, primarily among the members of the university's sports club and their network of contacts. Additionally, the research used internet portals intended for people who were interested in running and linked with groups who participate in this type of sports activity. The control group survey was conducted on social messaging platforms intended for students attending the university where the study was conducted, as well as the female family and friends of these students. The survey contained questions on, among other things, details related to training sessions, including the duration of a single training session, the frequency of the training sessions, and the distance run in each training session. In addition, the questions in the survey concerned details about the monthly cycle of the women runners, as well as their type of diet, and the amount of water consumed daily. At the end of the survey, the runners were asked a question to verify their knowledge of the female athlete triad. The question was: "Do you know what Female Athlete Triad is? If YES, please write..."

The control group questionnaire was slightly modified. The detailed running questions were removed, as was the question 'Do you use a 'special diet' for athletes, e.g., low calorie, high protein, vegetarian?" This question was amended to one in which participants were asked to answer yes or no to the question "Do you use a 'special diet', e.g., low calorie, high protein, vegetarian?" This question was followed by "If yes, which diet"?

Peer) reviewing PDF | (2021:08:65090:2:0:NEW 28 Dec 2021) 
152

153

154

155

156

157

158

159

160

161

162

163

164

165

166

167

168

169

170

171

172

173

174

175

176

177

178

179

180

181

182

In the research, the term 'special diet' was used to mean any diet used in a conscious manner or according to pre-established rules to which the respondents adhered, as well as any that the athletes themselves considered appropriate for them.

\section{Statistical Analyses}

Statistical analyses were performed using the SPSS 27 software program (Version 27.0, IBM Corp., Armonk, NY, USA). Two types of analyses were performed. The first compared the results of the group of running women and the control group. The second examined possible correlates and predictors of menstrual disorders.

Means, medians, standard deviations, as well as minima and maxima were used to describe numerical data (continuous) and for dichotomous and qualitative data - numbers and percentages. Due to the lack of normal distribution, the comparison of both groups for numerical variables was carried out using the Mann-Whitney $U$ test, and for dichotomous and qualitative variables the chi-square test was used. Correlations were calculated using Spearman's rho correlation coefficients. Multiple ordinal PLUM (Polytomous Logit Universal Model) regression analyses were used to analyse the predictors of menstrual disorders determined on the basis of the question "Have you ever missed your period for a long time after a period of regular bleeding? 1 - Yes, for less than 3 months, 2 - Yes, for between 3 and 6 months, 3 - Yes, for more than 6 months, 0 - I have never had such a situation." The potential predictors of menstrual disorders that were investigated included age, body mass index (BMI), diet, hydration of the runners, and details of run intensity including their time, frequency, or distance. Results where $\mathrm{p}<0.05$ were considered statistically significant.

\section{Results}

Compared to the women who did not regularly participate in physical activity, the female runners were characterized by their lower body weight. Runners vs. control showed a median body weight $60 \mathrm{~kg}$ vs. $65 \mathrm{~kg}(\mathrm{p}<0.001)$ and median BMI $21.63 \mathrm{~kg} / \mathrm{m}^{2}$ compared to $23.34 \mathrm{~kg} / \mathrm{m}^{2}$ for that of controls $(\mathrm{p}<0.001)$ (Table 1$)$.

This research showed differences between the monthly cycle of women who run and women who lead a sedentary lifestyle. The female runners had shorter periods of monthly bleeding, with a mean of 4.79 days relative to 5.27 days for controls $(\mathrm{p}<0.001)$, and the number of regular 
183 cycles over the year was smaller than in the control group with a mean of 9.62 cycles per year 184 compared to 11.22 for that of the control group $(\mathrm{p}<0.001)$ (Table1). There was also a difference 185 between runners and control related to the frequency with which they experienced 24-day

186 187 188 189 190 191 192 193 194 195 196 197 198 199 200

201

202

203

204

205

206

207

208

209

210

211

212 213

menstrual cycles, with $10.14 \%$ of runners and $3.5 \%$ of controls experiencing cycles of this duration ( $\mathrm{p}<0.05)$. In addition, runners experienced menstrual cycles of 25-31 days less frequently than the control group: $75.58 \%$ of runners reported experiencing longer cycles compared to $86.71 \%$ of controls $(p<0.05)$ (Table 2 ). There were no statistically significant difference between the runner and control groups in the proportion of monthly cycles longer than 31 days (Table 2). Despite the difference in the length of monthly cycles described above, the intra-group analysis showed that both runners and the control group predominantly had cycles of 25-31 days. The incidence of this cycle duration was significantly more frequent than longer cycles ( $>31$ days) or shorter cycles ( $<25$ days). There was no statistical difference between the two groups of women when comparing how often they missed their menstrual periods or in the incidence of spotting between periods.

Female runners showed an increased incidence of painless menstrual bleeding relative to control ( $23.96 \%$ vs. $7.69 \%$, respectively, $p<0.05)$. The female runners also reported fewer instances of menstruation that was painful only at the beginning of the bleeding period $(70.97 \%$ vs. $84.62 \%$, respectively, $\mathrm{p}<0.05)$. The incidence of menstrual pain throughout the bleeding period did not differ significantly between the groups (Table 2). When reported on a numerical scale, the degree of pain did not differ significantly between groups. In the runners group, when asked "whether, in their opinion, running leads to changes in the level of pain during menstruation" $30.41 \%$ replied that running reduces pain, and only $0.92 \%$ said that running during menstruation increased pain. The dominant answer was that running did not modify the perceived degree of pain during menstruation (56.68\%).

The runners, more often than the control group, used 'special diets' (28.70\%) vs. (13.29\%) (Table 2), and also drank more water. The most popular diet among the runners was a vegan or vegetarian diet, which was observed by 25 people (11.52\%). A healthy balanced diet was practiced by 10 people (4.61\%), and a low-calorie diet was practiced by 8 people (3.69\%). Highprotein diets, ketogenic diets, and gluten-free diets were also reported by 4, 2, and 3 participants, respectively. Other specific diets, such as diabetic and dairy-free diets, were mentioned by 3 people $(1.38 \%)$ and 8 people $(3.69 \%)$ did not detail the exact diet. Runners drank a minimum of

Peer) reviewing PDF | (2021:08:65090:2:0:NEW 28 Dec 2021) 
$2142.00 \mathrm{~L}$ of water a day vs. only $1.00 \mathrm{~L}$ that was consumed by the control group (median, $\mathrm{p}<0.001$ ).

215 Runners drank a maximum of 2.50 L relative to the $1.00 \mathrm{~L}$ consumed by control (median, $216 \mathrm{p}<0.001)$ (Table 1).

217 For runners, correlation analysis showed that the older the women were, the shorter their

218 monthly bleeding lasted, and it was less painful $(\mathrm{p}<0.01)$ (Table 3). Less pain during

219 menstruation was also experienced by runners who developed menarche at an older age, the

220 athletes who reported running longer distances, and women who had longer training times per

221 session. In the control group, the data showed the strongest correlation between increased age 222 and a decrease in the perception of menstrual pain (Table 4).

223 Regression analyses were only performed for the runners (Figure 1). The assumption of 224 equal regression coefficients important for ordinal regression, for each predictor in each 225 cumulative category of the dependent variable was satisfied $\times 2(24)=4.70 ; p=0.999$.

226 Nagelkerke's pseudo-R-square value was 0.25 . The overall model fit test did not yield a 227 statistically significant result $\mathrm{X} 2(12)=14.99 ; \mathrm{p}=0.242)$, but some predictors were statistically 228 significant (Figure 1). The use of a 'special diet' was a positive predictor of amenorrhea (Figure $2291)$.

230 The runners were asked "Do you know what Female Athlete Triad is? Please tell us what 231 you think it is. "In response to this question, 75.93\% replied that they knew nothing about it. The 232 remaining women replied with varying degrees of accuracy, mainly emphasizing that the triad 233 was "amenorrhea" (15.74\%), or that it was, for example, energy imbalance or eating disorders $234(2.77 \%)$. The triad syndrome, consisting of three interrelated elements, i.e., eating disorder, 235 menstrual disorders, and osteoporosis, was correctly described by only $5.56 \%$ of the women 236 surveyed.

237

\section{Discussion}

Sports-related menstrual disorders are complex, multi-factorial conditions that can have 240 serious consequences for the health of women. There are many factors that may contribute to

241 menstrual disorders in athletics, including strenuous training, stress related to exercise and 242 competition, body fat percentage, and genetic factors. It is, however, low energy availability 243 which is the most likely predisposing cause (Mountjoy et al., 2018). 
This study showed that the recreational runners, compared to women in the control group

245 who did not regularly participate in physical activity, had a lower body weight and lower BMI.

246 In addition, they had fewer regular monthly cycles per year, their menstrual bleeding was

247 shorter, and they had slightly more spotting between menstrual periods. Moreover, it was found

248 that the runners had cycles every 24 days, which was more often than the control group and

249 cycles of 25-31 days less frequently than the control group. There was no difference between the

250 groups in the proportion of cycles longer than 31 days, indicating that the runners did not suffer

251 from infrequent menstruation. However, the question arises as to whether the increased

252 frequency of short cycles in the runners might not be the first symptom in the shortening of the

253 luteal phase and a prelude to the cessation of menstruation. However, despite the fact that

$25475.58 \%$ of the runners declared cycles ranging from 21 to 31 days, i.e., falling within the

255 definition of a regular cycle covering from 21 to 31 days, in our own research, the occurrence of

256 ovulation in the examined women was not checked, and this is important because the research of

257 Shangold et al. (1990) showed that, in spite of the occurrence of a regular monthly cycle, there

258 are ovulation disorders and non-ovulatory cycles in those women who participate in sports. The

259 authors found that even if sportswomen had a regular, standard monthly cycle, as many as $50 \%$

260 of the female runners with eumenorrhea were not ovulating compared with $83 \%$ of the control

261 group. De Souza (De Souza 2003) stated that disorders of the luteal phase, characterized by poor

262 endometrial maturation as a result of inadequate progesterone production and short luteal phases,

263 are associated with infertility and habitual spontaneous abortions. In recreational athletes, the 3-

264 month sample prevalence and incidence rate of lymphoproliferative disorders and anovulatory

265 menstrual cycles is 48\% and 79\%, respectively (De Souza 2003). The above-mentioned studies,

266 therefore, support the assertion that female athletes who have regular monthly cycles can,

267 nevertheless, have problems such as chronic anovulatory cycles or a defect luteal phase

268 (Vilšinskaitė et al 2019).

269 The incidence of secondary amenorrhea in the general population who do not participate in 270 sports ranges from $2 \%$ to $5 \%$. Reports on the frequency of amenorrhea in the sports population

271 vary widely, mainly due to the differences in methodology between studies, and range from $6 \%$

272 to 79\% (Matzkin et al., 2015; De Souza et al., 2017; Beals et al., 2017; Daily et al., 2018;

273 Williams et al., 2017). This study showed that $30.88 \%$ of runners suffered from menstrual

274 disorders lasting less than 3 months, 10.14\% of runners between 3 and 6 months, and 5.07\% of 
275 runners over 6 months. In the physically inactive control group, the percentage of women with 276 similar disorders was $21.68 \%, 7.69 \%$ and $4.90 \%$, respectively. The percentage of women in both 277 groups who had never experienced a cessation of their menstrual cycle is more favourable for 278 women in the control group, 65.73\% vs. 53.92\%. However, these differences did not reach 279 statistical significance.

280 In both groups, significantly more women indicated that they felt pain only at the beginning 281 of menstruation, rather than pain throughout the duration of menstruation, or painless 282 menstruation. It was noteworthy that the runners reported much more often than the control 283 group that their menstrual bleeding was painless. The differences between the groups in the 284 assessment of pain on the numerical scale were not statistically significant. However, $30.41 \%$ of the women reported pain reduction as a result of running, indicating a possible analgesic effect of 286 physical activity. These results may point to the analgesic and muscle-relaxing effect of movement, which is confirmed by other authors of studies assessing the impact of physical activity on symptoms related to the monthly cycle (Sammon et al., 2016; Vishnupriva et al., 289 2011; Dehnavi et al., 2018; Azhary et al., 2005).

Interestingly, the findings of the authors' own research has shown that the distance and time spent on each run were important in the assessment of the pain occurring during menstrual bleeding. Women running longer distances and spending more time on each run reported less pain during menstruation. There are several hypotheses in the literature on the subject of the effect of exercise on the relief of menstrual pain symptoms. One such hypothesis is that a diminution of menstrual symptoms occurs when the equilibrium is disturbed in the hypothalamic-pituitary-ovarian axis. This may be caused by exercise-induced stress or weight 297 loss.

In addition, physical effort increases blood flow in the human body, improves metabolism, oxygenates tissues, and thus induces muscle relaxation. Furthermore, physical activity contributes to the release of beta-endorphins, which have an analgesic effect, and may therefore contribute to the alleviation of menstrual pain. It seems that the results of this research can be related to the above-mentioned hypotheses, and the longer the physical effort lasts, the longer the positive physiological effects associated with it are reflected in a woman's body (Golomb at al., 304 1998). 
305

306

307

308

309

310

311

312

313

314

315

316

317

318

319

320

321

322

323

324

325

326

327

328

329

330

331

332

333

334

In this study, the correlation analysis showed that the age of the runners correlated negatively with the cessation of the menstrual cycle, the duration of menstruation, the reported painfulness of the period, and the degree of pain during menstruation. Following correlation analysis, results in the runner group are similar to those obtained by other researchers of the subject, in which it has been shown that young athletes experience menstrual disorders much more often than mature women practicing the same sport, 67\% vs. 9\% (De Souza et al., 2017).

Less pain was also associated with runners who experienced menarche at an older age. The gynecologic age of the athlete seems to be even more important, i.e., the difference between the chronological age and the menarche age. Loucks et al. (2003) found in their research that, due to the lack of energy in patients with a gynecologic age from 14 to 18 years of age, the decrease in the frequency of luteinizing hormone secretion was not as high as in patients with a gynecologic age from 5 to 8 years. It has also been shown that women between the ages of 25 and 40 who participated in an exercise program, together with a calorie restricted eating plan, experienced only a few disruptions to the regularity of their menstrual cycle.

A woman's age is an important factor that has a significant impact on the course of the menstrual cycle. In this study, it was shown for both groups that the older a woman is, the lower the level of pain experienced during menstruation. This is reflected in the literature, where it has been shown that dysmenorrhea is more common in young women. For example, in the age range 17-24 years, dysmenorrhea affects $67 \%$ to $90 \%$ of women, while in adult women rates vary from $15 \%$ to $75 \%$, and in mature women only $7 \%$ to $15 \%$ experience severe pain that limits their daily functioning (Hong et al., 2014).

It would be outside the scope of this study to analyse the diet of athletes. Nevertheless, having the knowledge that menstrual disorders in sport occur mostly as a result of low energy availability resulting from dietary restrictions, the runners were asked whether they followed any 'special diet' (e.g., ketogenic, vegetarian, vegan) that was especially any intended for athletes.

The nutritional habits of the runners in terms of the amount of nutrients contained in their meals were not studied. The question was aimed only at the general recognition of whether the women undertaking recreational running pay attention to what they eat, whether they have knowledge about the existence of diets for athletes, or whether they generally care about their eating habits used in sport. 
The use of a 'special diet', i.e., one that the athletes themselves considered appropriate, was

336

337

338

339

340

341

342

343

344

345

346

347

348

349

350

351

352

353

354

355

356

357

358

359

360

361

362

363

364

365

a positive predictor of the occurrence of amenorrhea and the use of a 'special diet' was conducive to the cessation of the menstrual cycle. Among the runners, $28.70 \%$ declared that they used a 'special diet', while among the control group this was only $13.29 \%$. When analysing the answers to the question about the types of diet, however, it is difficult to designate them as specific diets for athletes. A detailed analysis of the responses from runners showed that the most frequently declared diets were a vegan or vegetarian diet and, less frequently, a balanced/healthy diet. The authors of this study, however, are not in a position to confirm that the diet actually was well balanced and what, exactly, the runners considered a 'healthy' diet. Additionally, some of the women declared using a low-calorie diet, and some participants also referenced high-protein and gluten-free diets. Only two women reported using a specific diet for athletes. Such answers suggest that the runners lack knowledge about the obligation to supplement the caloric deficit, which may arise in connection with the practiced sports discipline, and could directly lead to disorders of the menstrual cycle. The results obtained indicate an urgent need to restore the energy balance in the bodies of the women runners. Following 'special diets' without dietician and nutritionist recommendations or guidance may contribute to females not ingesting enough to meet their energy needs.

The runners' knowledge about the FAT turned out to be negligible. In this study only $24.07 \%$ of the recreational runners declared they "knew something" about the concept of FAT in sport, which means that $75.92 \%$ did not know what syndrome they were being asked about. However, when analysing the accuracy of the answers given by the runners, it turned out that only $5.56 \%$ gave the correct answer, and most often the women stated that, according to them, only the loss of the monthly cycle was caused by athletic activity. It is disturbing that a lack of knowledge about FAT is common among people who have practiced sports on a regular basis for many years, albeit on a recreational basis (Larsen et al., 2020; Kroshus et al., 2018).

Identifying FAT, especially in young female athletes, can sometimes be difficult as the health consequences may not be immediately apparent and therefore not easy to recognize. However, any woman with at least one component of FAT should be assessed for possible other components of the condition. Primary prevention should focus on education about the existence, signs, and symptoms of FAT in sport and this should be a priority among all health care professionals, coaches, and caregivers involved in the health and optimal psycho-physical

Peer) reviewing PDF | (2021:08:65090:2:0:NEW 28 Dec 2021) 
366

367

368

369

370

371

372

373

374

375

376

377

378

379

380

381

382

383

384

385

386

387

388

389

390

391

392

393

394

395

396

condition of female athletes (Klein et al., 2019; Lebrun 2007). Given the small amount known about FAT among healthcare representatives and trainers (Berz et al., 2016; Thomas et al., 2016), every effort should be made to include information about FAT in the curriculum of the various medical professions.

The limitations of the study included a lack of full dietary analysis, self-reported menstrual cycle characteristics, and determination of menstrual cycle features from survey vs. tracking for 3-6 months.

\section{Conclusions}

Compared to women in the control group, who did not exercise, recreational runners had shorter and less regular monthly cycles and shorter monthly bleeding. It was also found that women running longer distances and spending more time on each run reported less pain during menstruation.

Based only on general information about the runners' diets, without any testing of the nutritional values contained in their meals, it can be concluded that type of diet may contribute to the cessation of the menstrual cycle.

\section{References}

Azhary S, Karimi Chatrudi A, Attarzadeh R, Mazloom R. 2005. Officacy of group aerobic exercise program on the intensity of premenstrual syndrome. Iranian Journal of Obstetrics, Gynecology and Infertility 8:119-128

Beals KA, Meyer NL. 2017. Female Athlete Triad Update. Clinical Journal of Sport Medicine 26:69-89

Berz K, McCambridge T. 2016. Amenorrhea in the Female Athlete: What to Do and When to Worry. Pediatric Annals 45:e97-e102

Castelo-Branco C, Reina F, Montivero AD, Colodron M, Vanrell JA. 2006. Influence of highintensity training and of dietetic and anthropometric factors on menstrual cycle disorders in ballet dancers. Gynecological Endocrinology 22:31-35

Civil R, Lamb A, Loosmore D, Ross L, Livingstone K, Strachan F, Dick JR, Stevenson EJ, Brown MA, Witard OC. 2018. Assessment of Dietary Intake, Energy Status, and Factors Associated With RED-S in Vocational Female Ballet Students. Frontiers in Nutrition 5:136 

45:615-624

De Souza MJ, Koltun KJ, Etter CV, Southmayd EA. 2017. Current Status of the Female

400

401

402

403

404

405

406

407

408

409

410

411

412

413

414

415

416

417

418

419

420

421

422

423

424

425

426

427 Athlete Triad: Update and Future Directions. Current Osteoporosis Reports 15:577-587 De Souza MJ. 2003. Menstrual disturbances in athletes: a focus on luteal phase defects. Medicine and Science in Sports and Exercise 35:1553-1563

Dehnavi ZM, Jafarnejad F, Goghary SS. 2018. The effect of 8 weeks aerobic exercise on severity of physical symptoms of premenstrual syndrome: a clinical trial study. BMC Women's Health 18:80

George ChA, Leonard JP, Hutchnson MR. 2011. The female athlete triad: a current concepts review. South African Journal of Sports Medicine 23:50-55

Golomb LM, Solidum AA, Warren MP. 1998. Primary dysmenorrhea and physical activity. Medicine \& Science in Sport \& Exercise 30:906-909

Hong J, Jones M, Mishra G. 2014 The prevalence and risk factors of dysmenorrhea. Epidemiologic Reviews 36:104-113

Klein DA, Paradise SL, Reeder RM. 2019. Amenorrhea: A Systematic Approach to Diagnosis and Management. American Family Physician 100:39-48

Kroshus E, DeFreese JD, Kerr ZY. 2018. Collegiate Athletic Trainers' Knowledge of the Female Athlete Triad and Relative Energy Deficiency in Sport. Journal of Athletic Training 53:51-59

Larsen B, Morris K, Quinn K, Osborne M, Minahan C. 2020. Practice does not make perfect: A brief view of athletes' knowledge on the menstrual cycle and oral contraceptives. Journal of Science and Medicine in Sport 23:690-694

Lebrun CM. 2007. The Female Athlete Triad: What's a Doctor to Do? Current Sports Medicine Reports 6:397-404

Loucks AB. 2003. Energy availability, not body fatness, regulates reproductive function in women. Exercise and Sport Sciences Reviews 31:144-148

Lynch SL, Hoch AZ. 2010. The Female Runner: Gender Specifics. Clinics in Sports Medicine 29:477-498

Macleod AD. 1998. Sport psychiatry. Australian and New Zealand Journal of Psychiatry $32: 860-866$ 
428

429

430

431

432

433

434

435

436

437

438

439

440

441

442

443

444

445

446

447

448

449

450

451

452

453

454

455

456

457

458

Matzkin E, Curry EJ, Whitlock K. 2015. Female Athlete Triad: Past, Present, and Future. Journal of the American Academy of Orthopaedic Surgeons 23:424-432

Mountjoy M, Sundgot-Borgen J, Burke L, Ackerman K, Blauwet Ch, Constantini N, Lebrun C, Lundy B, Melin AK, Meyer NL, et al. 2018. IOC consensus statement on relative energy deficiency in sport (RED-S): 2018 update. British Journal of Sports Medicine 52:687-697

Sawai A, Mathis BJ, Natsui H, Zaboronok A, Mitsuhashi R, Warashina Y, Mesaki N, Shiraki H, Watanabe K. 2018. Risk of female athlete triad development in Japanese collegiate athletes is related to sport type and competitive level. International Journal of Women's Health 10:671-687

Schofield KL, Thorpe H, Sims ST. 2020. Compartmentalised disciplines: Why low energy availability research calls for transdisciplinary approaches. Performance Enhancement and Health 8:100172

Shangold M, Rebar RW, Wentz AC, Schiff I. 1990. Evaluation and management of menstrual dysfunction in athletes. Journal of the American Medical Assotiation 263:1665-1669

Sim A, Burns SF. 2021. Review: questionnaires as measures for low energy availability (LEA) and relative energy deficiency in sport (RED-S) in athletes. Journal of Eating Disorders 9:41

Stefani L, Galanti G, Lorini S, Beni G, Del M, Maffull N. 2016. Female athletes and menstrual disorders: a pilot study. Muscles, Ligaments, and Tendons Journal 6:183-187 Thomas DT, Erdman KA, Burke LM. 2016. American College of Sports Medicine Joint Position Statement. Nutrition and Athletic Performance. Medicine and Science Sports and Exercises 48:543-568

Thompson SH. 2007. Characteristics of the Female Athlete Triad in Collegiate Cross-Country Runners. Journal of American College Health 56:129-136

Tosi M, Maslyanskaya S, Dodson NA, Coupey SM. 2019. The Female Athlete Triad: A Comparison of Knowledge and Risk in Adolescent and Young Adult Figure Skaters, Dancers, and Runners. Journal of Pediatric and Adolescent Gynecology 31:165-169

Vilšinskaitė DS, Vaidokaitė G, Mačys Ž, Bumbulienė Ž. 2019. The risk factors of dysmenorrhea in young women. Wiadomości Lekarskie 6:1-5

Vishnupriva R, Rajarajeswaram P. 2011. Effects of Aerobic Exercise at Different Intensities in Pre Menstrual Syndrome. The Journal of Obstetrics and Gynecologyof India 61:675-682 
459 Westerbeek HM. 2009. The Amsterdam Olympic Games of 1928 and 2028: will city heritage 460 inform legacy intent? Sport Social 12:776-791

461 Williams NI, Mallinson RJ, De Souza MJ. 2019. Rationale and study design of an

462 intervention of increased energy intake in women with exercise-associated menstrual

463 disturbances to improve menstrual function and bone health: The REFUEL study.

464 Contemporary Clinical Trials Communication14:100325

465 Williams NI, Statuta SM, Austion A. 2017. Female Athlete Triad Future Directions for

466 Energy Availability and Eating Disorder Research and Practice. Clinical Journal of Sport

467 Medicine 36:671-686

468

469 
Figure 1

Figure 1: Results of the PLUM coefficient regression of the predictors of amenorrhea in the group of female runners ( $\mathrm{N}=217$ ), (Regression Coefficient and $95 \%$ confidence intervals). 
What is the maximum number of litres you drink in a day?

What is the minimum number of litres you drink in a day?

Do you use a special diet for athletes?

What is the maximum number of hours for one run?

What is the minimum number of hours for one run?

What is the maximum number of times you run in a week?

What is the minimum number of times you run in a week?

What is the maximum distance you run? [km]

What is the minimum distance you run? [km]

How long have you been running for?

BMI [kg/m2]

Age [years]

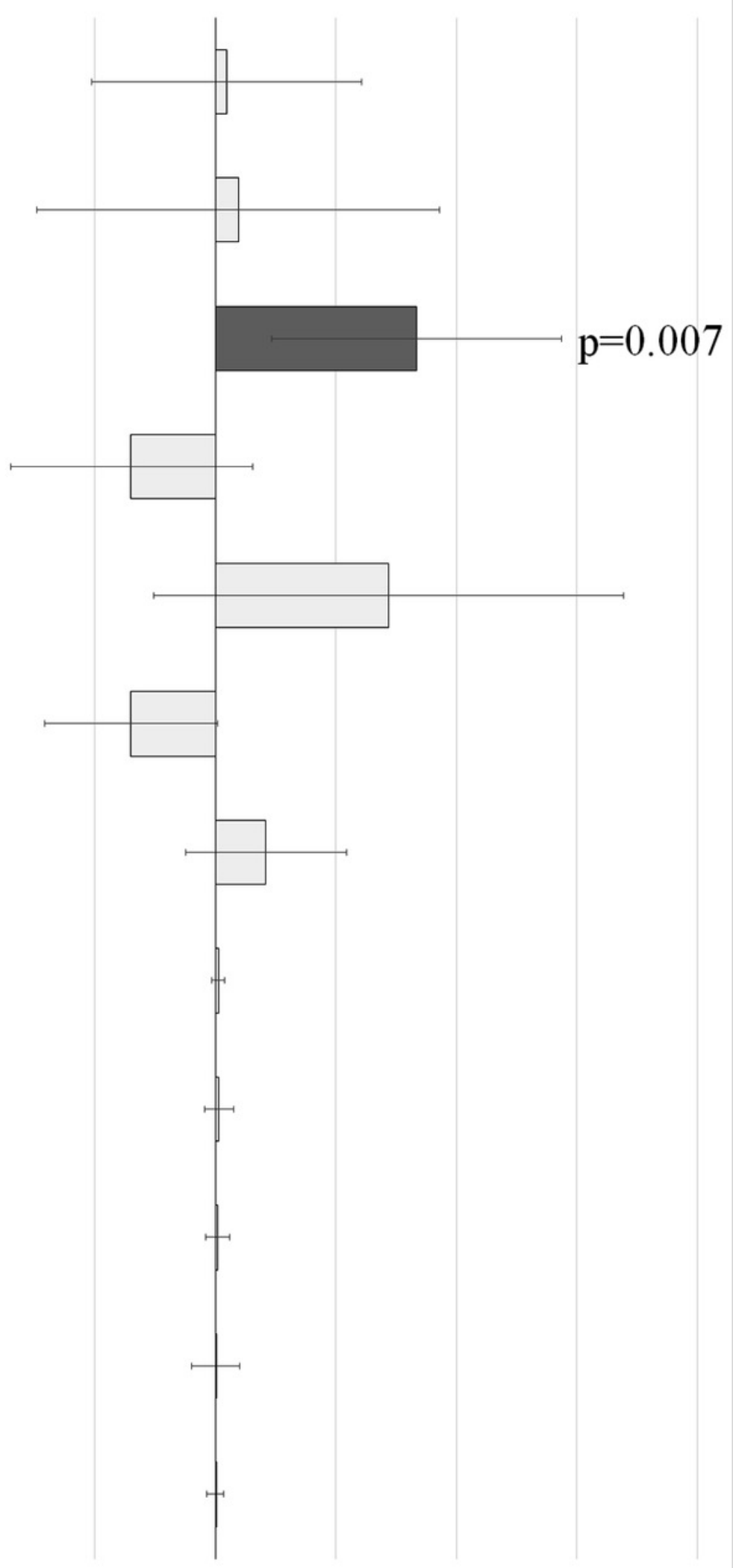

$\begin{array}{lllllll}-2 & -1 & 0 & 1 & 2 & 3 & 4\end{array}$ 
Figure 2

Figure 1: Results of the PLUM coefficient regression of the predictors of amenorrhea in the group of female runners ( $\mathrm{N}=217$ ), (Regression Coefficient and 95\% confidence intervals). 
What is the maximum number of litres you drink in a day?

What is the minimum number of litres you drink in a day?

Do you use a special diet for athletes?

What is the maximum number of hours for one run?

What is the minimum number of hours for one run?

What is the maximum number of times you run in a week?

What is the minimum number of times you run in a week?

What is the maximum distance you run? [km]

What is the minimum distance you run? [km]

How long have you been running for?

BMI $[\mathrm{kg} / \mathrm{m} 2]$

Age [years]

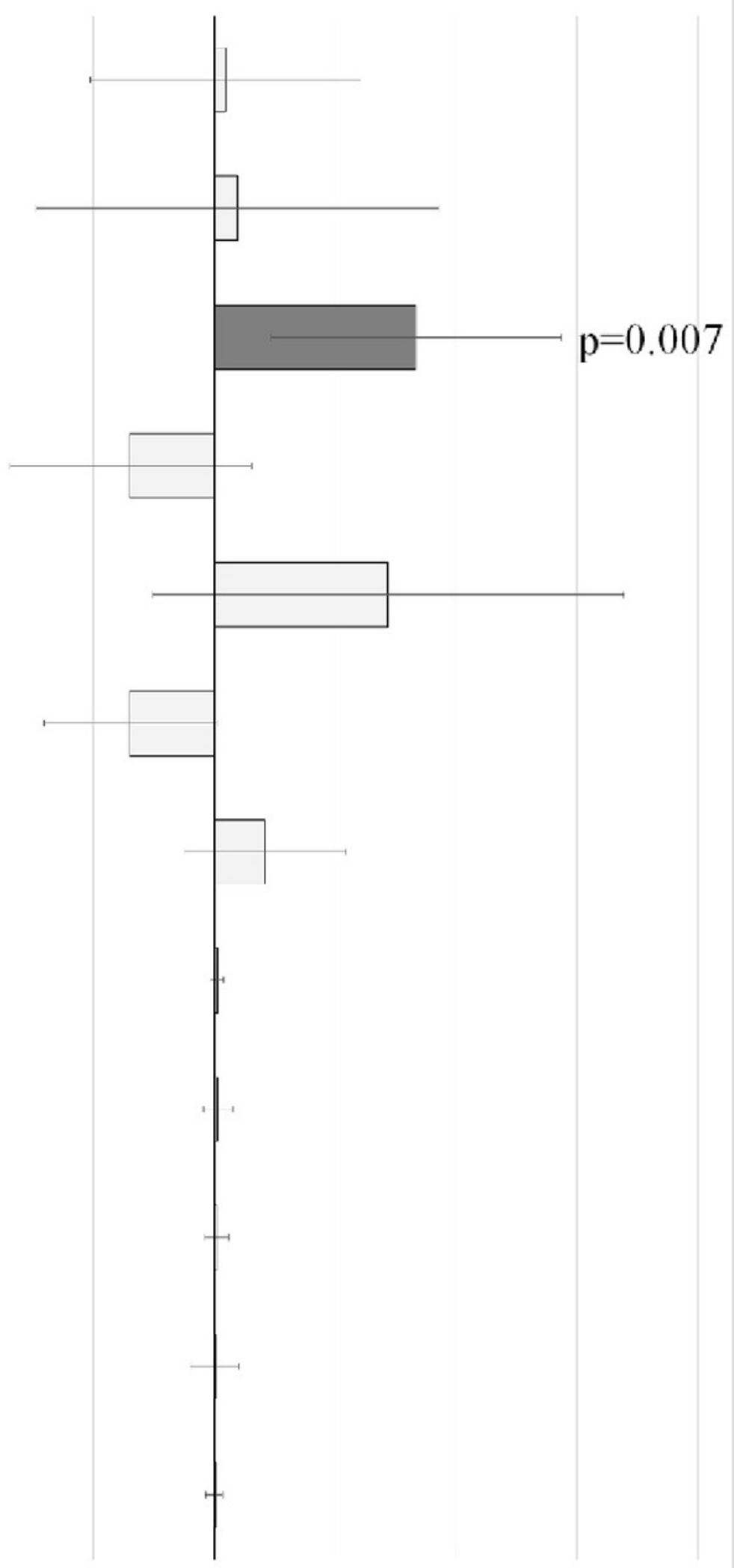

$-2 \quad-1$
2 


\section{Table $\mathbf{1}$ (on next page)}

Table 1: Anthropometric parameters, length of menstrual bleeding, number of regular monthly cycles, training characteristics, hydration and 'special diet' 
1 Table 1: Anthropometric parameters, length of menstrual bleeding, number of regular monthly cycles, training characteristics, hydration and 'special diet' in groups $\mathbf{R}$ - runners $(\mathrm{N}=217)$ and $\mathrm{C}-$ control $(\mathrm{N}=143)_{2-}$ (the Mann-Whitney $U$ test, the $\chi^{2}$ test, $p-$ level of 4 significance).

\begin{tabular}{|c|c|c|c|c|c|c|c|c|}
\hline \multirow{2}{*}{ Dependent Variable } & \multicolumn{2}{|c|}{ Average } & \multicolumn{2}{|c|}{ Medians } & \multicolumn{2}{|c|}{$\begin{array}{l}\text { Standard } \\
\text { Deviation }\end{array}$} & \multirow[t]{2}{*}{$\mathrm{U}$} & \multirow[t]{2}{*}{$\mathrm{p}$} \\
\hline & $\mathrm{R}$ & $\mathrm{C}$ & $\mathrm{R}$ & $\mathrm{C}$ & $\mathrm{R}$ & $\mathrm{C}$ & & \\
\hline Age [years] & 32.06 & 31.90 & 32.00 & 31.00 & 8.38 & 8.85 & -.37 & .711 \\
\hline Height $[\mathrm{cm}]$ & 166.24 & 167.17 & 165.00 & 168.00 & 5.92 & 6.35 & -1.49 & .135 \\
\hline Body weight [kg] & 61.72 & 67.96 & 60.00 & 65.00 & 10.33 & 13.43 & -4.45 & $<.001$ \\
\hline $\mathrm{BMI}\left[\mathrm{kg} / \mathrm{m}^{2}\right]$ & 22.30 & 24.28 & 21.63 & 23.34 & 3.29 & 4.40 & -4.44 & $<.001$ \\
\hline $\begin{array}{l}\text { How many days does } \\
\text { menstruation last? }\end{array}$ & 4.79 & 5.27 & 5.00 & 5.00 & 1.25 & 1.11 & -3.67 & $<.001$ \\
\hline $\begin{array}{l}\text { How many regular } \\
\text { menstrual cycles have } \\
\text { you had in the last year? }\end{array}$ & 9.62 & 11.22 & 11.00 & 12.00 & 3.27 & 1.42 & -4.49 & $<.001$ \\
\hline $\begin{array}{l}\text { How many years have } \\
\text { you been running? }\end{array}$ & 5.47 & - & 4.00 & - & 5.01 & - & - & - \\
\hline $\begin{array}{l}\text { What is the minimum } \\
\text { distance you run? }[\mathrm{km}]\end{array}$ & 6.88 & - & 5.00 & - & 3.70 & - & - & - \\
\hline $\begin{array}{l}\text { What is the maximum } \\
\text { distance you run? }[\mathrm{km}]\end{array}$ & 19.20 & - & 15.00 & - & 11.43 & - & - & - \\
\hline $\begin{array}{l}\text { What is the minimum } \\
\text { number of times you run } \\
\text { in a week? }\end{array}$ & 3.24 & - & 3.00 & - & 1.20 & - & - & - \\
\hline $\begin{array}{l}\text { What is the maximum } \\
\text { number of times you run } \\
\text { in a week? }\end{array}$ & 4.04 & - & 4.00 & - & 1.25 & - & - & - \\
\hline $\begin{array}{l}\text { What is the minimum } \\
\text { number of hours for one } \\
\text { run? }\end{array}$ & 1.03 & - & 1.00 & - & .38 & - & - & - \\
\hline $\begin{array}{l}\text { What is the maximum } \\
\text { number of hours for one } \\
\text { run? }\end{array}$ & 1.45 & - & 1.00 & - & .67 & - & - & - \\
\hline
\end{tabular}




\begin{tabular}{|c|c|c|c|c|c|c|c|}
\hline $\begin{array}{l}\text { What is the minimum } \\
\text { number of litres of water } 1.77 \\
\text { you drink in a day? }\end{array}$ & 1.51 & 2.00 & 1.50 & .61 & .56 & -3.95 & $<.001$ \\
\hline \multirow{3}{*}{$\begin{array}{l}\text { What is the maximum } \\
\text { number of litres of water } 2.43 \\
\text { you drink in a day? }\end{array}$} & 1.66 & 2.50 & 1.50 & .76 & .64 & -6.27 & $<.001$ \\
\hline & & \multicolumn{2}{|c|}{ Runners } & \multicolumn{2}{|c|}{ Control } & \multirow{2}{*}{$\chi^{2}$} & \multirow{2}{*}{$\mathrm{p}$} \\
\hline & & $\mathrm{N}$ & $\%$ & $\mathrm{~N}$ & $\%$ & & \\
\hline Do you use a 'special diet'? & yes & 62 & 28.70 & 19 & 13.29 & 11.71 & 0.001 \\
\hline \multicolumn{2}{|l|}{ Typ of 'special diet' of runners: } & $\mathrm{N}$ & $\%$ & & & & \\
\hline \multicolumn{2}{|l|}{ Vegan or vegetarian } & 25 & 11.52 & & & & \\
\hline \multicolumn{2}{|l|}{ Balanced diet } & 10 & 4.61 & & & & \\
\hline \multicolumn{2}{|l|}{ Low calorie } & 8 & 3.69 & & & & \\
\hline \multicolumn{2}{|l|}{ High-protein } & 4 & 1.84 & & & & \\
\hline \multicolumn{2}{|l|}{ Ketogenic } & 2 & 0.92 & & & & \\
\hline \multicolumn{2}{|l|}{ Gluten free } & 3 & 1.38 & & & & \\
\hline \multicolumn{2}{|c|}{$\begin{array}{l}\text { Other specific diets, such as diabetic and } \\
\text { dairy-free diets }\end{array}$} & 3 & 1.38 & & & & \\
\hline \multicolumn{2}{|c|}{$\begin{array}{l}\text { Lak of information about type of 'special } \\
\text { diet' }\end{array}$} & 8 & 3.69 & & & & \\
\hline
\end{tabular}

5 


\section{Table 2 (on next page)}

Table 2: Characteristics of the monthly cycle of the women surveyed and the use of 'special' diet in the groups $\mathrm{R}$ - runners $(\mathrm{N}=217)$ and $\mathrm{C}$ - control $(\mathrm{N}=143)(\mathrm{X} 2$ test, $\mathrm{p}$ level of significance for whole categorical variable). 
1 Table 2: Characteristics of the monthly cycle of the women surveyed and the use of 'special 2 diet' in the groups $R$ - runners $(N=217)$ and $C$ - control $(N=143)$ ( $x^{2}$ test, $p$ - level of 3 significance for whole categorical variable).

4 Different letters (a, b) denote significant group differences for a given category of the 5 categorical variable at $\boldsymbol{p}<\mathbf{0 . 0 5}$, the same letters $(\mathrm{a}, \mathrm{a})$ denote lack of group differences for a 6 given category of the categorical variable at $\boldsymbol{p}<\mathbf{0 . 0 5}$. Different letters $(\mathbf{x}, \mathbf{y})$ denote differences 7 between categories within groups at $p<0.05$, the same letters $(x, x)$ denote lack of differences 8 between categories within groups at $p<0.05$.

9

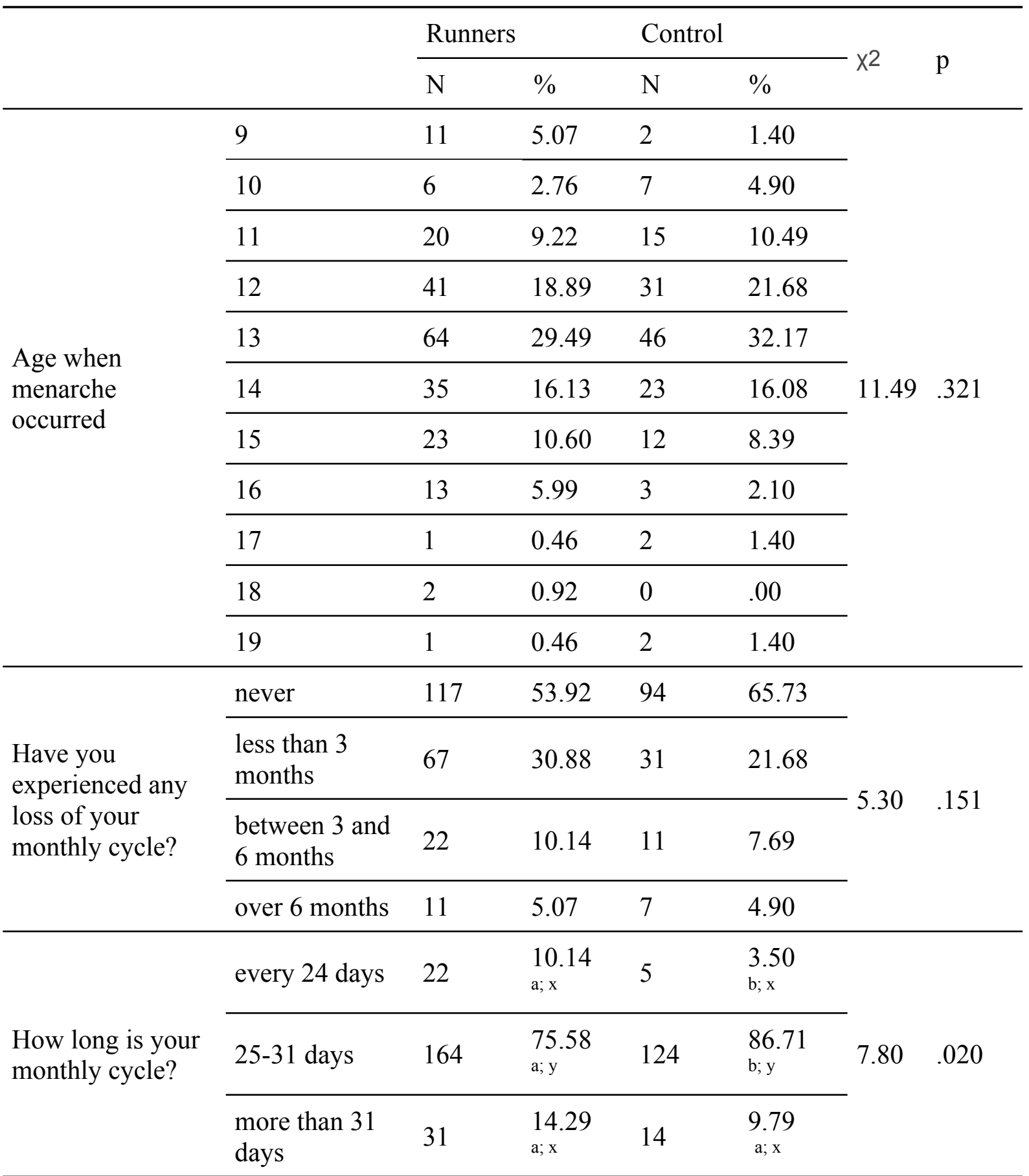




\begin{tabular}{|c|c|c|c|c|c|c|c|}
\hline \multirow{3}{*}{$\begin{array}{l}\text { Is menstruation } \\
\text { painful? }\end{array}$} & painless & 52 & $\begin{array}{l}23.96 \\
a ; x\end{array}$ & 11 & $\begin{array}{l}7.69 \\
b ; x\end{array}$ & \multirow{3}{*}{16.11} & \multirow{3}{*}{$<.001$} \\
\hline & $\begin{array}{l}\text { painful at the } \\
\text { beginning }\end{array}$ & 154 & $\begin{array}{l}70.97 \\
\text { a; y }\end{array}$ & 121 & $\begin{array}{l}84.62 \\
b ; y\end{array}$ & & \\
\hline & $\begin{array}{l}\text { painful } \\
\text { throughout }\end{array}$ & 11 & $\begin{array}{l}5.07 \\
a ; x\end{array}$ & 11 & $\begin{array}{l}7.69 \\
\mathrm{a}, \mathrm{x}\end{array}$ & & \\
\hline \multirow{11}{*}{$\begin{array}{l}\text { The degree of pain } \\
\text { experienced } \\
\text { during } \\
\text { menstruation }\end{array}$} & 0 & 15 & 6.91 & 10 & 6.99 & \multirow{11}{*}{4.98} & \multirow{11}{*}{.893} \\
\hline & 1 & 20 & 9.22 & 11 & 7.69 & & \\
\hline & 2 & 18 & 8.29 & 7 & 4.90 & & \\
\hline & 3 & 24 & 11.06 & 14 & 9.79 & & \\
\hline & 4 & 20 & 9.22 & 16 & 11.19 & & \\
\hline & 5 & 20 & 9.22 & 14 & 9.79 & & \\
\hline & 6 & 36 & 16.59 & 20 & 13.99 & & \\
\hline & 7 & 24 & 11.06 & 18 & 12.59 & & \\
\hline & 8 & 24 & 11.06 & 24 & 16.78 & & \\
\hline & 9 & 7 & 3.23 & 4 & 2.80 & & \\
\hline & 10 & 9 & 4.15 & 5 & 3.50 & & \\
\hline \multirow{4}{*}{$\begin{array}{l}\text { The effect of } \\
\text { training on } \\
\text { menstruation pain }\end{array}$} & lessens the pain & 66 & 30.41 & - & - & - & - \\
\hline & $\begin{array}{l}\text { increases the } \\
\text { pain }\end{array}$ & 2 & 0.92 & - & - & - & - \\
\hline & has no effect & 123 & 56.68 & - & - & - & - \\
\hline & $\begin{array}{l}\text { I don't train } \\
\text { during my } \\
\text { period }\end{array}$ & 26 & 11.98 & - & - & - & - \\
\hline $\begin{array}{l}\text { Do you experience } \\
\text { spotting between } \\
\text { periods? }\end{array}$ & yes & 54 & 25.00 & 33 & 23.08 & 0.17 & .677 \\
\hline $\begin{array}{l}\text { Do you use a } \\
\text { 'special diet'? }\end{array}$ & yes & 62 & 28.70 & 19 & 13.29 & 11.71 & .001 \\
\hline
\end{tabular}




\section{Table 3(on next page)}

Table 3: Analysis of the correlation between the features of the monthly cycle and anthropometric parameters, training characteristics and nutrition in the group of runners ( $\mathrm{N}=217$ ), (Spearman's rho correlation ${ }^{*} \mathrm{p}<0.05,{ }^{* *} \mathrm{p}<0.01$ ). 
1 Table 3: Analysis of the correlation between the features of the monthly cycle and 2 anthropometric parameters, training characteristics and nutrition in the group of runners 3 (N=217), (Spearman's rho correlation * $\left.\mathbf{p}<\mathbf{0 . 0 5},{ }^{* *} \mathbf{p}<\mathbf{0 . 0 1}\right)$. 4

\begin{tabular}{llllllll}
\hline & & & & & \\
& & &
\end{tabular}


of hours for one run?

\begin{tabular}{llllllll}
\hline $\begin{array}{l}\text { Age when } \\
\text { menarche occurred }\end{array}$ & -.04 & -.11 & -.03 & .04 & -.11 & $-.21^{* *}$ & -.07 \\
\hline $\begin{array}{l}\text { Do you use a } \\
\text { 'special diet'? }\end{array}$ & .11 & -.09 & -.09 & -.05 & -.07 & -.05 & -.01 \\
\hline $\begin{array}{l}\text { What is the } \\
\text { minimum number } \\
\text { of litres you drink } \\
\text { in a day? }\end{array}$ & .12 & -.04 & -.05 & .08 & -.06 & $-.14^{*}$ & -.06 \\
\hline $\begin{array}{l}\text { What is the } \\
\text { maximum number } \\
\text { of litres you drink }\end{array}$ & .17 & -.04 & .01 & -.12 & .00 & -.11 & $-.31 *$ \\
in a day? & & & & & & & \\
\hline
\end{tabular}




\section{Table 4 (on next page)}

Table 4: Analysis of the correlation between the features of the menstrual cycle and anthropometric parameters as well as nutrition in the control group ( $N=143)$ (Spearman's rho correlation $* p<0.05$, ${ }^{* *} p<0.01$ ). 
1 Table 4: Analysis of the correlation between the features of the menstrual cycle and anthropometric parameters as well as nutrition in the control group ( $N=143)$, (Spearman's rho correlation *p<0.05, ** $\mathbf{p}<0.01$ ).

4

\begin{tabular}{|c|c|c|c|c|c|c|c|}
\hline $\begin{array}{l}\text { Control } \\
\text { Group }\end{array}$ & 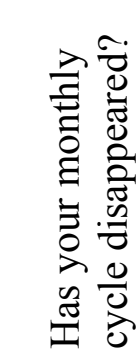 & 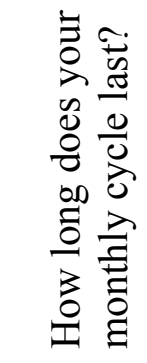 & 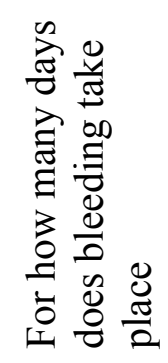 & 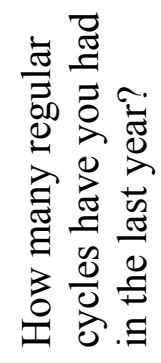 & 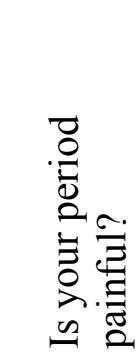 & 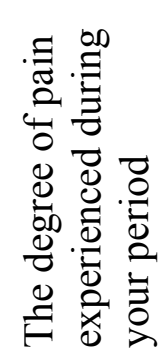 & 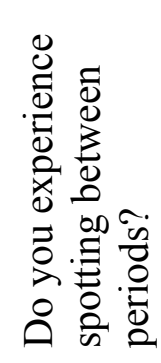 \\
\hline Age [years] & -.16 & .04 & $-.20 *$ & .12 & -.16 & $-.34 * *$ & -.08 \\
\hline Height $[\mathrm{cm}]$ & -.08 & .01 & .03 & -.02 & .02 & .06 & .02 \\
\hline Body weight [kg] & .14 & .04 & -.12 & -.11 & .01 & -.04 & .06 \\
\hline BMI [kg/m2] & $.19 *$ & .02 & -.16 & -.11 & .00 & -.07 & .06 \\
\hline $\begin{array}{l}\text { At what age did } \\
\text { menstruation first } \\
\text { start? }\end{array}$ & .08 & .05 & .04 & .01 & .14 & .01 & -.02 \\
\hline $\begin{array}{l}\text { Are you on a } \\
\text { 'special diet'? }\end{array}$ & .15 & -.07 & $.19 *$ & .01 & -.11 & -.12 & .03 \\
\hline $\begin{array}{l}\text { What is the } \\
\text { minimum number } \\
\text { of litres you drink } \\
\text { in a day? }\end{array}$ & $.17 *$ & -.07 & .07 & -.15 & .07 & .02 & .01 \\
\hline $\begin{array}{l}\text { What is the } \\
\text { maximum } \\
\text { number of litres } \\
\text { you drink in a } \\
\text { day? }\end{array}$ & .11 & -.13 & .08 & -.10 & .04 & -.02 & .08 \\
\hline
\end{tabular}

